\title{
A CONVERSÃO DE CONHECIMENTO ATRAVÉS DO "LEARNING BY HIRING" NO PROGRAMA EMBRAER 170/190
}

\author{
1- Ricardo Gentil Peixoto da Costa \\ IBMECRJ \\ ricardo.gentil@turbomeca.com.br
}

\author{
3- Luiz Alberto Nascimento Campos Filho \\ IBMECRJ \\ lafilho@ibmecrj.br
}

\author{
2- Henrique Pazos Siqueira Boclin \\ Federação das Indústrias do Estado do Rio \\ de Janeiro - FIRJAN
}

Diego Maganhotto Coraiola - Editor

\section{RESUMO}

Fim da década de 1990. A Embraer prepara-se para lançar um novo programa de aeronaves, denominado Embraer 170/190. Este programa representará um passo importante para a empresa, que almeja, através dele, consolidar sua posição dentre os líderes mundiais na produção de aeronaves civis a jato e atingir um nicho de mercado ainda inexplorado. Mas a empresa não conta com todas as tecnologias de que necessita, decidindo por buscar no mercado internacional profissionais que the aportem as tecnologias de base das quais necessita. Como converter em conhecimento da empresa o conhecimento trazido por estes especialistas internacionais numa indústria de intensivo conhecimento tecnológico? Este artigo, baseado na revisão bibliográfica e no estudo do caso sobre o programa Embraer 170/190, explora a maneira como a Embraer conseguiu vencer este desafio, através da conversão do conhecimento mediante o Aprendizado pela Contratação, Learning by Hiring, colaborando para o estudo acadêmico do tema, em linha com a literatura existente no momento.

Palavras-Chave

Conhecimento, EMBRAER, “Learning by Hiring”.

\section{ABSTRACT}

In the end of the '90s, Embraer had made its decision to launch a new aircraft program, named Embraer 170/190. This program represented an important challenge for Embraer, because it would place the company among the leaders in civil Aircraft industry, as well as venture into an unexplored market niche. But the company did not have all the necessary technologies, deciding, then to search the international market for specialists in the fields of knowledge it needed. How can a Brazilian aircraft manufacturer company competing in a knowledge-intensive sector handle this kind of situation? Based on literature review and a case study of the $170 / 190$ program at Embraer this article presents in what manner Embraer manage this challenge converting knowledge brought by migrating professionals through Learning by Hiring. The results reinforced what is supported in the knowledge conversion literature.

Keywords

Knowledge, EMBAER, Learning-by-Hiring. 


\section{Introdução}

$\mathrm{Na}$ arena competitiva global as empresas rapidamente igualam e ultrapassam diferenciais competitivos de eficiência, atendimento diferenciado etc. A disputa não é mais focada nos ativos tangíveis e sim, na capacidade das empresas de capturar e transformar o conhecimento (BARTELETT, GOSHAL E BIRKINSHAW, 2004).

Nas últimas décadas observou-se um crescente interesse do meio acadêmico e empresarial sobre as questões relativas à gestão do conhecimento (ARGOTE, MCEVILY; REAGANS, 2003; NONAKA; VON KROGH; VOELPEL, 2006). Artigos e livros como os de Prusak e Davenport (1995), Nonaka (1991), Nonaka, Von Krogh e Voelpel (2006), Santos e Doz (2004), enfatizaram que o Conhecimento Empresarial é um dos mais valiosos ativos que uma organização pode possuir. Especialmente nas Knowledge Intensive Firms (KIF), segundo Starbuck (1992), o Conhecimento e sua gestão são decisivos para a vantagem competitiva das empresas sobre seus concorrentes. As empresas do setor aeronáutico são KIFs e é nele que a empresa multinacional brasileira Embraer se insere. No final da década de 1990, a Embraer decidiu investir no desenvolvimento de uma linha de aeronaves para disputar o espaço de mercado entre os regional commuters e as aeronaves de médio porte: 0 Programa Embraer 170/190. Com ele a Embraer buscou atingir um segmento de aeronaves de médio porte, com capacidade entre 70 e 100 passageiros, ainda não por grandes empresas do setor, como Airbus e Boeing. No entanto, para desenvolver este programa, a Embraer necessitava de conhecimento que não estava disponível na empresa e nem no mercado brasileiro. Haviam opções para o desenvolvimento do projeto tais como sub-contratar projetos, contratar consultores e firmas especializadas, que foram adotadas para partes não relacionadas às competências essenciais da empresa. Todavia, para desenvolver e manter suas competências essenciais, a empresa necessitava de técnicos e engenheiros qualificados, em quantidades e com especialidades não disponíveis no mercado brasileiro. A empresa buscou, então, a contratação em outros países de profissionais que pudessem integrar-se às equipes brasileiras, num esforço de transferência e expansão dos conhecimentos, que, aliado à formação interna de novos profissionais, the proveria os conhecimentos necessários às novas aspirações.
O presente artigo visa apresentar o fluxo de conhecimento criado pela Embraer para o desenvolvimento de suas linhas de aeronaves Embraer 170/190, por meio da contratação de técnicos e especialistas estrangeiros para o projeto.

O tema Learning by Hiring está ainda por explorar. Ettlie (1985), em seu artigo intitulado Learning-by-hiring: when is mobility is more likely to facilitate interfirm knowledge transfer?, declarou: "o uso da mobilidade como um mecanismo de aprendizado inter-firmas recebeu pouca atenção formal ou estudo rigoroso".

\section{Referencial Teórico}

O objetivo desta seção é apresentar linhas teóricas sobre a Gestão do Conhecimento. São explicadas teorias sobre 0 conhecimento; 0 conhecimento nas organizações; a transferência e conversão do conhecimento; os fluxos e fontes de conhecimentos utilizados pelas empresas; finalizando com teorias sobre a transferência de conhecimento pela contratação e migração de especialistas.

\section{a) Conhecimento}

Daft (2003, p. 239) define que Conhecimento é "uma conclusão tirada das informações, depois que elas foram ligadas a outras informações e comparadas com aquilo que já se conhece". Davenport e Prusak (1998, p. 48), por sua vez, propõem uma definição funcional sobre Conhecimento. Segundo eles, "conhecimento é uma mistura fluida de experiência condensada, valores, informação contextual e insight experimentado, a qual proporciona uma estrutura para a avaliação e incorporação de novas experiências". Nonaka e Takeuchi (1997, p. 1179) complementam-na ao afirmarem que 0 Conhecimento está "incorporado aos indivíduos, sendo dependente da história, sensível ao contexto, específico e direcionado à definição de problema, mais que à descrição ou solução do problema".

Grant (2005), Davenport e Prusak (1998) classificam o conhecimento em duas categorias conforme sua facilidade de codificação expressão e, conseqüentemente, de transferência:

- Conhecimento Explícito: pode ser codificado e registrado em forma de documentos, informação, podendo ser replicado inúmeras vezes para vários usuários a um custo relativamente baixo. A proteção deste tipo de 
conhecimento pode ser feita através de medidas de segurança, como registro de propriedade intelectual ou de patentes, dentre outras.

- Conhecimento Tácito: ao contrário do Explícito, não é passível de codificação, podendo apenas ser observado e adquirido na prática, sendo sua transferência entre as pessoas custosa e de resultados imprevisíveis. Sua proteção é igualmente difícil de ser feita.

Todo conhecimento é gerado a partir da Informação, como definido por Daft (2003). Para se entender como a informação se transforma em Conhecimento, recorre-se a Davenport e Prusak (1998), que definiram que a transformação da informação em conhecimento se dá por quatro formas:

- A Comparação entre as informações com outras anteriormente adquiridas;

- A associação de Conseqüências que estas informações trazem para a tomada de decisão;

- O estabelecimento de Conexões entre o conhecimento atual e aquele anteriormente acumulado;

E da Conversação entre os indivíduos visando à análise e ao compartilhamento de opiniões sobre as informações.

\section{b) Conhecimento no âmbito das organizações}

Segundo Argote, McEvily e Reagans (2003), a pesquisa sobre aprendizado e conhecimento organizacionais tem uma longa história: Adam Smith, ao relatar sobre o processo de fabricação de alfinetes, descreve um processo de aprendizado pela execução; Marshall propôs que boas idéias são rapidamente assimiladas e comentadas por pessoas da mesma região; Max Weber descreveu a "capacidade da burocracia de aprender" pela experiência.

Segundo Nonaka, Von Krogh e Voelpel (2006), a partir da década de 1980 é que a Epistemologia organizacional $^{1}$ desenvolveu seus conceitos e passou a estudar os fenômenos de geração, transformação e transferências de conhecimento nas organizações. Os artigos de Nonaka (1991), Kogut e Zander (1992), Grant (1996) convergem para uma caracterização de Conhecimento Organizacional através de três linhas:
- É a crença numa verdade justificada, compartilhada pelos membros da organização (NONAKA; TAKEUCHI, 1995);

- É a capacidade de definir uma situação e agir consistentemente com o que esta demanda (STEHR, 1992);

- Pode ser explícito ou tácito (NONAKA, 1991).

Grant (2005), caracteriza os tipos de conhecimento organizacionais, no âmbito da estratégia empresarial, em:

- Saber Como (Know-How) - conhecimento tácito por natureza, normalmente envolvendo habilidades das pessoas e, por natureza, de transferência mais difícil.

- Saber Sobre (Know-About) - normalmente explícito, compreendendo as teorias, procedimentos e instruções. Por sua natureza e formato, o Saber Sobre é transferível entre indivíduos, no tempo e no espaço.

c) Conhecimento organizacional: aquisição, criação, expansão e transferência

Em artigo sobre a criação de Conhecimento Organizacional, Nonaka, Von Krogh e Voelpel (2006, p. 1179) definiram que Criação de Conhecimento Organizacional é "o processo de tornar disponível e amplificar o conhecimento criado pelos indivíduos, assim como cristalizá-lo e conectá-lo ao sistema de conhecimento da organização", e terminando por concluir que o Conhecimento pode ser criado

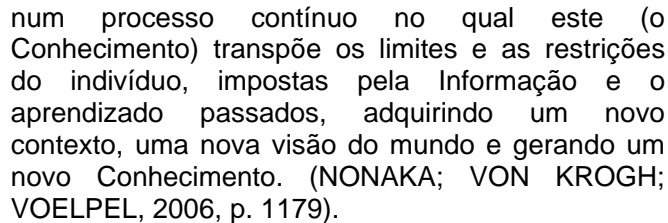

Ainda segundo estes autores, o Conhecimento nas organizações é Criado ou Expandido através de um Processo de Conversão, em quatro etapas:

- Socialização - objetiva compartilhar o conhecimento Tácito entre os indivíduos;

- Externalização - objetiva traduzir o conhecimento Tácito em Explícito;

- Combinação - combina diferentes conhecimentos Explícitos e, finalmente;

- Internalização - completa o ciclo, incorporando o conhecimento Explícito ao Tácito. 
Tanto a Criação quanto a Transferência de Conhecimento se dão, segundo Nonaka, Von Krogh e Voelpel (2006), em um ambiente, que pode ser físico, mental ou virtual. Neste ambiente, os indivíduos exercitam o processo de Criação, Expansão e Transferência de conhecimentos. À Organização caberá organizar, promover e ordenar este ambiente. A organização de Equipes de Projetos está dentre as formas de fomento à criação de ambientes que promovam o desenvolvimento de conhecimentos.

Nadler, Thompson e Van Boven (2003) demonstraram que, quando se trata de transferir Conhecimentos Tácitos, a melhor maneira de fazêlo é através da observação e do uso de canais de comunicação que utilizem múltiplas fontes de informação, forneçam feedback fácil e rápido e permitam aos interlocutores imprimirem na comunicação traços e particularidades pessoais. Depreende-se daí a importância do contato físico, verbal e visual entre os indivíduos que detêm o conhecimento e aqueles aos quais se deseja transferi-lo.

Dois desafios à Criação e Transferência de Conhecimento por meio de equipes atuando em um ambiente (físico ou virtual) delimitado para sua interação são enumerados:

- Grant (2001) - Para permitir a otimização do processo de Criação e Transferências de Conhecimentos, as equipes devem ter relações fortes e positivas e uma atmosfera de grupo que favoreça os ganhos com experiências coletivas, geração de idéias e transmissão do conhecimento tácito.

- Zalenick (1985) - Nos aspectos de criatividade, a formação de grupos locais tende a reduzir a criatividade, tendendo a uma visão míope, conservadora e reforçadora de padrões do próprio grupo.

Este último ponto pode ser ainda complementado e corroborado pelo resultado da pesquisa a respeito da Globalização de Conhecimento, realizada por Santos e Doz (2004). Esta pesquisa compilou e analisou dados relativos ao estudo de 45 empresas multinacionais e internacionais, na Europa e EUA, e concluiu que "há maior probabilidade para uma inovação emergir a partir de interação conhecimentos oriundos de diversas fontes diversificadas e geograficamente dispersas do que de um agrupamento local, de conhecimento concentrado" Santos e Doz (2004, p. 34), que complementam informando que as origens deste Conhecimento estão não apenas outras empresas, mas em localizações geográficas bastantes distintas, inclusive internacionalmente.

Além disto, em sua pesquisa sobre a valorização do conhecimento gerado externa e internamente às organizações, Menon e Pfeffer (2003) observaram que as pessoas tendem a valorizar mais os conhecimentos gerados fora de seu ambiente de trabalho. Deste modo, conclui-se que as organizações podem gerar mais e melhor conhecimento através da migração e da interação, em um mesmo ambiente, de indivíduos e, conseqüentemente, de conhecimentos, de origens diversas.

\section{d) Fontes de conhecimento: sua localização e fluxo}

Howells, James e Malik (2003) e Song, Almeida e Wu (2003) sugerem que cada vez mais as empresas reconhecem que é difícil gerar e explorar por si próprias todo o Conhecimento de que necessitam para seu contínuo desenvolvimento. As pesquisas de Mansfield (1968) já indicavam que a maioria das fontes de inovações estava fora das empresas que as utilizam, acrescentando que a razão disto é que as empresas consideram ser mais barato e rápido buscar conhecimento já desenvolvido do que tentar desenvolvê-lo por si próprias.

Howells, James e Malik (2003) observaram uma tendência generalizada entre as empresas multinacionais de alta-tecnologia de busca e uso de Conhecimento e Tecnologia, já desenvolvida ou a ser desenvolvida, externamente à organização. Sua pesquisa analisou quais são as fontes externas de Conhecimento mais comumente buscadas pelas empresas, concluindo que o tipo de origem é dependente do tempo: as empresas optam por parcerias e alianças com outras organizações ao buscarem conhecimento a ser desenvolvido, em relações de longo prazo. E optam por mecanismos de contratação temporária de especialistas, troca informal de conhecimentos e contratação de licenças, quando buscam conhecimentos já existentes, ao qual desejam ter acesso num prazo curto. No entanto estes mesmos autores relataram, ainda, que este processo de busca externa por conhecimento é altamente dinâmico e interativo, muitas vezes exigindo que a organização trave contatos paralelos e simultâneos com diversas fontes de conhecimento (ex.: universidades, centro de pesquisa, especialistas). Assim, conclui-se que a organização que busca Conhecimentos necessários ao seu desenvolvimento deverá estar informada e em contato com os centros de excelência e com os referenciais de mercado para 
o tipo do Conhecimento buscado, a fim de poder adquiri-lo por uma das vias possíveis, dependendo de sua urgência no acesso ao Conhecimento.

Segundo Zander e Kogut (1995), a extensão na qual as empresas podem buscar conhecimentos externamente é dependente da natureza do conhecimento buscado. Uma vez que o conhecimento sobre o estado da arte das tecnologias é geralmente tácito e desenvolvido internamente a um grupo, sua transferência entre empresas é mais complexa e difícil. Assim, concluise que é mais fácil transferir-se conhecimento relativo a tecnologias periféricas e não àquela básica e altamente especializada de uma dada indústria. Diversos mecanismos, como as licenças, as alianças e associações e a contratação de profissionais, são utilizados para a aquisição e transferência de conhecimentos.

\section{e) Fontes de conhecimento: aquisição, transferência e conversão de conhecimento pela contratação de profissionais}

Desde a década de 1980, autores como Ettlie(1985), Argote e Ingram (2000); Szulanski (1996), Jafffe (1986) estudaram a transferência de conhecimento entre empresas por meio da migração de profissionais. Nestes estudos, a mobilidade dos indivíduos é identificada como um fator importante para a transferência de conhecimento entre as organizações. No âmbito das transferências de pessoas entre empresas, Argote e Ingram (2000) observaram que uma grande parte do conhecimento buscado pelas empresas está contido em indivíduos e concluíram que a mobilidade destes indivíduos entre organizações gera a transferência de conhecimento inter-organizacional.

Aharoni (1991), Cohen e Levinthal (1990), citados no artigo de Wong, Shaw e Sher (1999), evidenciaram que o processo de transferência de tecnologia implica em aprendizado organizacional que será realizado a partir da aquisição de conhecimento de fontes externas e pelo desenvolvimento interno da tecnologia. Wong, Shaw e Sher (1999, p. 433) complementam esta citação ressaltando que: "aprender a utilizar o novo conhecimento tecnológico é um fator essencial para a transferência de tecnologia e requer o comprometimento dos gerentes para a criação de uma organização orientada para o aprendizado".

Szulanski (1996) e Jaffe (1986), por sua vez, verificaram que a mobilidade humana desempenha um papel importante no desenvolvimento de conhecimento pelas empresas que contratam profissionais de outras empresas, particularmente se o conhecimento buscado está agregado e localizado em certas empresas, regiões ou países.

No entanto, Zander e Kogut (1995) evidenciaram que é a natureza do conhecimento que determina até que ponto as empresas podem buscá-lo exteriormente. Organizações cujos Conhecimentos sejam codificáveis, parametrizáveis e passíveis de acumulação e recuperação têm, obviamente, mais facilidade de transferi-los através da contratação. Em oposição, conhecimentos de natureza tácita são mais difíceis de serem adquiridos por contratação, tendendo a serem criados e transmitidos internamente aos grupos.

Adicionalmente Dosi (1984), como o conhecimento, especialmente aquele do tipo tácito, é difícil de ser "separado das pessoas" que o detêm, a contratação de pessoas de outras empresas concorrentes é uma maneira de transferir conhecimento que seria, de outra maneira, imóvel. Em complementação, Song, Almeida e Wu (2003) observaram que a transferência do conhecimento tácito através das fronteiras de empresa é um desafio considerável, visto que o conhecimento tácito se transmite mais facilmente intra-grupos que inter-grupos, especialmente aqueles localizados remotamente uns em relação aos outros.

Um outro ponto relevante é abordado por Starbuck (1992), que concluiu que as empresas "aprendem" mais através da troca de profissionais que os próprios profissionais isoladamente. No entanto ele ressalta que a chegada de novos profissionais à empresa causa uma instabilidade naqueles que já se encontram nela, o que pode causar bloqueios na transferência de conhecimentos. E complementa que a troca freqüente de profissionais enfraquece as relações entre a firma e seus empregados, como a adesão e a lealdade.

A pesquisa de Song, Almeida e Wu (2003) a respeito da influência da contratação de profissionais nas transferências de conhecimento entre organizações confirma as hipóteses de que:

- As organizações que buscam expandir suas bases de conhecimento para novas áreas tecnológicas podem aproveitar da mobilidade de especialistas, com bons resultados;

- Os melhores resultados vem da contratação de especialistas possuidores de um nível de conhecimento acima daquele existente na organização; 
- O nível de transferência tecnológica aumenta quando as organizações contratam especialistas cujo conhecimento é distante daquele por elas dominado e o utilizam em áreas fora de sua core competence.

Song, Almeida e Wu (2003, p. 362) expõem ainda dois motivos diferentes para a busca de Conhecimento através da contratação:

- Empresas que ainda não "dominam" uma dada tecnologia tendem a contratar especialistas oriundos de competidores como forma de acesso ao conhecimento que necessitam dominar.

- Empresas que já dominam o estado da arte de uma tecnologia buscam especialistas que agreguem mais qualidade ao seu capital humano, por meio da experiência de inserção de conhecimentos externos à organização.

E concluem destacando que "a busca por conhecimento externo é especialmente importante para as economias emergentes que buscam estreitar a lacuna tecnológica existente entre elas mesmas e as nações mais desenvolvidas" (SONG; ALMEIDA; WU, 2003, p. 362).

Nelson e Winter (1982) sugerem que a busca por novos conhecimentos é função do estágio de desenvolvimento da organização. Organizações que tenham necessidade de se lançar e competir em novos mercados são mais propensas a buscar conhecimentos externamente e serem receptivas a este conhecimento.

O aprendizado através da contratação não apenas permite $o$ acesso e a transferência imediatos dos conhecimentos necessários, mas também facilita a "transferência de capacidades", o que levará a novos desenvolvimentos de conhecimento, segundo Kim (1997). A partir do pressuposto de que a contratação de profissionais experientes é um caminho viável para a aquisição de conhecimentos, deve-se analisa a hipótese que a influência da localização geográfica dos profissionais contratados, de forma a otimizar a Transferência e Conversão do Conhecimento, é relevante. A respeito da localização geográfica do grupo de indivíduos formado para a criação e a expansão do Conhecimento, Santos e Doz (2004) observaram que a escolha da estratégia de Transferência de Conhecimentos depende de dois fatores:

- A Complexidade de Conhecimento do Mercado

\section{- A Complexidade do Conhecimento Técnico}

Santos e Doz (2004) propuseram um modelo para auxiliar as organizações na escolha da modalidade de transferência a ser adotada, o qual é mostrado na Figura 1, a seguir.

mecanismo de aporte dos profissionais à empresa), qualificados a serem implantados em grupos locais de especialistas para com eles interagirem e formarem novo conhecimento ou aperfeiçoarem o conhecimento existente.

Mova o conhecimento através do

dizio de pessoas e pela co-

alocação temporária

Mova a informação sobre o

mercado para onde a

tecnologia estiver

Figura 1 - Opções de modalidade de transferência.

técnico

criação de conhecimento advêm da migração profissionais, (mediante contratação ou outro
Deste modo, a partir desta teoria depreende-se que, para um mercado complexo e de alta tecnologia, os melhores resultados de expansão e 
Segundo Starbuck (1992), o conhecimento dos especialistas contratados externamente se converte, por meio dos diversos modelos de transferência anteriormente revistos, (itens $2.3 \mathrm{e}$ 2.4 desta seção), em três tipos de ativo (propriedade) da Organização: Capital (Físico e Social), Rotinas e Cultura Organizacional. Starbuck (1992) esclarece que Rotinas e Cultura Organizacional são as formas de se acumular e preservar os conhecimentos adquiridos, evitando que ele seja "perdido" quando os profissionais migram para novas posições e organizações.

Em seu trabalho sobre os modelos de criação e transferência de conhecimento, Nadler, Thompson e Van Boven (2003) verificaram que dentre as formas de aprendizado estudadas (baseada em princípios, revelação de Informação, analogia e observação) as mais eficazes foram aquelas em que o aprendizado ocorreu por meio do contato entre o aprendiz e o instrutor para a execução das tarefas, caracterizando a significância, para a transferência do conhecimento, da interação física entre os profissionais detentores de conhecimento e aqueles que estarão aprendendo e convertendo estes conhecimentos.

O estudo de Wong, Shaw e Sher (2000) sobre as formas de aprendizado organizacional na transferência de tecnologia demonstrou que as práticas de transferência de conhecimento, dentre elas o Learning by Hiring, se mostram mais eficazes em empresas onde há um ambiente favorável à absorção e retenção de novos conhecimentos. Tal ambiente organizacional é criado a partir de iniciativa pró-aprendizado, como a existência de políticas e práticas de gerenciais que valorizem o aprendizado e o conhecimento, a existência de programas e políticas específicos (como os de On-the Job Training) e o uso de sistemas de informação voltados para a "captura", a "guarda" e a "conversão" de conhecimentos.

\section{e) Fatores determinantes para a migração de mão- de-obra com alto conhecimento tecnológico}

Sendo a migração de profissionais experientes e qualificados uma importante fonte de Conhecimento para organizações multinacionais, é interessante analisar-se quais são os fatores que levam à migração destes, sob o ponto de vista da atratividade para os imigrantes. Mahroum (2000) realizou um estudo sobre a migração de profissionais altamente qualificados, e demonstrou que os profissionais são levados a migrarem atraídos (ou impelidos) por Fatores e por Políticas. Dentre os cinco tipos de migrantes altamente qualificados caracterizados em seu estudo são relevantes para o presente artigo as migrações de engenheiros e técnicos; e a de cientistas e acadêmicos. Mahroun (2000) enumerou os fatores e políticas determinantes da atratividade para a migração destes tipos de profissionais apresentados no Quadro 1, a seguir.

\begin{tabular}{|l|l|l|}
\hline $\begin{array}{l}\text { Tipo de } \\
\text { profissional }\end{array}$ & $\begin{array}{l}\text { Fatores (atrativos ou } \\
\text { propulsores) }\end{array}$ & Políticas \\
\hline $\begin{array}{l}\text { Engenheiros e } \\
\text { técnicos }\end{array}$ & $\begin{array}{l}\text { Econômicos (mecanismo de oferta } \\
\text { e procura) }\end{array}$ & $\begin{array}{l}\text { Legislação de imigração } \\
\text { Legislação tributária }\end{array}$ \\
\hline $\begin{array}{l}\text { Cientistas e } \\
\text { acadêmicos }\end{array}$ & $\begin{array}{l}\text { Prestígio da instituição } \\
\text { Natureza e condições de trabalho } \\
\text { Desenvolvimento científico }\end{array}$ & $\begin{array}{l}\text { Inter-institucionais } \\
\text { Inter-governamentais }\end{array}$ \\
\hline
\end{tabular}

Figura 2 - Fatores e políticas da atratividade para migração de profissionais

Fonte: Mahroun (2000)

Assim, podemos verificar que diversas linhas teóricas fundamentam o processo de transferência e conversão de conhecimentos através do Learning by Hiring e da conseqüente migração de profissionais detentores do conhecimento almejado por uma dada organização. Caberá à organização criar e gerenciar um modelo de Gestão do Conhecimento que favoreça a transferência entre os migrantes e as equipes já instaladas, de forma a otimizar o processo de transferência e conversão do conhecimento. O estudo de caso a seguir procurará identificar o contexto e os fatores relevantes relativos ao Learning by Hiring e à migração de profissionais no contexto do Programa Embraer 170/190.

\section{Desenvolvimento do Estudo de Caso}

Esta seção apresenta e analisa o caso do Programa de Desenvolvimento e Fabricação das 
aeronaves Embraer 170/190 nos aspectos relativos à da transferência de conhecimento por meio da migração de profissionais. A seção se inicia com um descritivo sobre a Embraer e a importância do conhecimento para seu negócio, passa a relatar o histórico e o contexto da transferência e criação de conhecimento na empresa e termina no estudo do Conhecimento aportado por especialistas estrangeiros contratados para o Programa Embraer 170/190, nos seus diversos aspectos e à luz dos conceitos apresentados na seção Referencial Teórico.

\section{a) Embraer e o desenvolvimento tecnológico}

Embraer é uma das empresas que mais crescem no Brasil. Ela é a quarta maior fabricante de aeronaves no mundo com mais de $30 \%$ do mercado de jatos regionais. A canadense Bombardier é seu principal competidor direto. Cerca de 95\% dos produtos da Embraer são exportados, principalmente para os Estados Unidos. A expectativa de faturamento para 2006 é de US\$ 3,95 bilhões e 85\% advém das vendas de jatos - o restante é resultado do setor de serviço e militar (GÓES E LACOMBE, 2007).

Segundo Drummond (2004), a indústria aeronáutica brasileira contou, desde o seu início, com a participação de estrangeiros para the agregar conhecimentos e auxiliar seu desenvolvimento. $O$ próprio Centro Técnico Aeroespacial - CTA, concebido segundo o modelo do MIT para um cluster de desenvolvimento tecnológico contou com a participação de cientistas e professores daquela instituição como "alavanca" para seu início (AMATO NETO, LUZ E GATTAZ, 2006). Ainda segundo Drummond (2004), tendo sido criada a partir de um plano que privilegiava e valorizava o desenvolvimento do conhecimento sobre as tecnologias aeronáuticas e em linha com o seu mercado, a Embraer desde o início acreditou na força do conhecimento como "mola propulsora" para a definição do seu futuro. Sua trajetória começa com o Bandeirante, chega aos jatos regionais da família ERJ 145 (presentes nos cinco continentes, nas mais importantes empresas aéreas mundiais) e passa à nova família de jatos comerciais EMB 170/190, cujos primeiros aviões entraram recentemente em operação.

Bernardes (2000) credita o sucesso da Embraer na concorrência por mercados internacionais, sobrepujando empresas de nações desenvolvidas se baseia no domínio do conhecimento e tecnologias, o que lhe permitiu orientar a melhoria de seus produtos e satisfazer clientes os mais exigentes.

Conforme registrado por Drummond (2004) e Cassiolato, Bernardes e Latres (2002), a partir do Projeto do EMB 326 Xavante, aeronave de reconhecimento e ataque montada sob licença da Aermacchi italiana, a Embraer passou a utilizar-se de alianças e acordos tecnológicos para o desenvolvimento de suas próprias aeronaves, o que lhe permitiu desenvolver e assimilar novas tecnologias, incorporando-as às suas competências. Deste modo, projetos como o argentino-brasileiro CBA-123 vector e o ítalobrasileiro AMX tiveram sua base tecnológica "alicerçada" pelo intercâmbio de profissionais entre empresas participantes das alianças e por acordos celebrados entre os governos, sendo natural para a Embraer a convivência com a transferência de tecnologia efetuada por estrangeiros.

No final da década de 1990, a Embraer decidiu investir no desenvolvimento de uma linha de aeronaves para disputar o espaço de mercado existente entre os regional commuters e as aeronaves de grande porte, explorando um segmento de mercado de aeronaves com capacidade entre 60 e 100 passageiros, pressurizadas e dotadas de motores tipo turbofan, até então não explorado por grandes empresas como Boeing e Airbus. A empresa necessitava de algumas competências técnicas para este desenvolvimento, mas não havia disponibilidade no mercado local de todos os conhecimentos necessários, nem em quantidade de profissionais e nem no domínio de conhecimentos específicos, segundo relatado por João e Flischman (2000).

\section{b) Novos programas e a demanda por novos conhecimentos}

Segundo o site internet da empresa, partir da década de 1990 a Embraer tornou-se líder mundial no segmento de mercado regional de aviação, ao mesmo tempo em que tem buscado o crescimento nos setores da aviação militar e executiva. E, como corroborado por Bernardes (2000), após a sua privatização, em 1994, a empresa adotou a estratégia de desenvolver e adaptar a plataforma de suas aeronaves por meio da introdução de novas tecnologias, onde pudessem ser criadas vantagens, seja pela diminuição do custo de aquisição, seja pela redução do custo operacional, seja por assegurar ao seu cliente mais confiabilidade, conforto e segurança. Durante os poucos anos que antecederam e sucederam o processo de privatização da empresa, as vendas 
de aeronaves estavam bem abaixo do esperado e, como conseqüência, a empresa teve de se desfazer de engenheiros que já haviam acumulado conhecimento, o que acabou por criar um "hiato de conhecimento" em seus quadros técnicos. De acordo com Sbragia e Terra (1993), a Embraer préprivatização não era dotada de uma organização dedicada a gerir o conhecimento crítico para a empresa, estando limitada à formação tradicional de recursos humanos e delegando aos departamentos técnicos a tarefa de armazenar os conhecimentos acumulados.

Em seu trabalho sobre a transferência de tecnologia na Embraer, Cassiolato, Bernardes e Latres (2002) ressaltaram que a aquisição de competência técnica no projeto de fuselagens foi considerada estratégica para o futuro da empresa. De acordo com executivos seniores da empresa, competência na Fuselagem foi considerada uma competência essencial a ser desenvolvida e sedimentada localmente. Isto foi considerado condição essencial para a autonomia no projeto dos produtos e para o futuro da empresa como integradora de aeronaves. Esta informação é corroborada no trabalho de Dagnino (1993), ao relatar que a Embraer tomou a decisão de não desenvolver conhecimento através da mera adaptação e modificação de produtos e processos estrangeiros, preferindo desenvolver-se seus recursos humanos nas áreas de pesquisa básica e aplicada, visando o desenvolvimento de soluções próprias em áreas do conhecimento consideradas estratégicas.

\section{c) Estratégia baseada no Conhecimento}

Drummond (2004) e Bernardes (2000) relatam que a Embraer chegou à conclusão de que não seria possível se basear somente no conhecimento interno de seus funcionários e fornecedores locais para realizar seus projetos, uma vez que a tendência mundial no setor era seguir o exemplo das montadoras de automóveis na década de 1990. A estratégia empresarial da Embraer, a partir disso, baseia-se no princípio segundo o qual não é importante fabricar os diferentes subsistemas, mas sim adicionar valor na integração das aeronaves, retendo a capacidade de combiná-los e adaptá-los de acordo com os requisitos do projeto. Assim, a empresa se concentrou em ativos estratégicos que Ihe permitiram coordenar uma rede de parceiros de risco e uma rede global de fornecedores, fortalecendo, assim, a competitividade. Daí a necessidade de se ter um modelo de Gestão do Conhecimento.
João e Fischmann (2000) descreveram as estratégias baseadas no conhecimento adotadas pela Embraer, segundo um modelo no qual o ativo Conhecimento é segmentado em três famílias, segundo sua origem: da Estrutura Externa à empresa (Clientes, fornecedores, parceiros de risco, instituições de ensino e pesquisa), da Estrutura Interna da empresa (Suas organizações de P\&D, Operacionais etc.) e da Competência Individual (que é o conhecimento acumulado pelos indivíduos). Segundo estes autores, a Embraer busca melhorar a transferência e a conversão do conhecimento através da interação entre estas três famílias, tendo a Embraer adotado uma estratégia ampla, abrangendo as nove combinações possíveis de transferência de conhecimentos entre as três famílias. Dentre estas combinações, são relevantes para explicar o modelo adotado pela Embraer para a transferência do conhecimento aportado pela migração de profissionais especializados:

- A Transferência/conversão de Conhecimento entre Indivíduos através da comunicação entre indivíduos dentro da organização, em trabalhos de equipe, aprendizagem e compartilhamento de Conhecimento.

- A Transferência/conversão de Conhecimento dentro da estrutura interna: mediante 0 reaproveitamento de conhecimento existente entre os projetos de aeronaves, especialmente através do uso de ferramentas de gerenciamento de conteúdo e de documentos disponíveis na Intranet da empresa, disponibilizados a todos que deles necessitam.

- A Transferência/conversão de conhecimento de competência individual para a estrutura interna: através da captura e disponibilização do conhecimento tácito - papel representado pela intranet e pelos sistemas de gestão de documentos a partir de conhecimento tácito dos funcionários e os seus colaboradores externos, incluindo consultores.

Transferência/conversão de conhecimento da estrutura interna para competência individual: que trata da necessidade de disponibilizar para outros indivíduos o conhecimento adquirido pela empresa. Simulações, ambientes de e-learning, criação de maquetes em realidade virtual e de sistemas de gestão do conhecimento estão contidas nesta estratégia. 
d) Projeto Embraer 170/190 e seu modelo de Gestão de Conhecimento

Desenvolvido a partir de 1999, o Programa Embraer 170/190 representou um salto tecnológico para a empresa. Segundo o Relatório sobre os Impactos Sócio-Econômicos dos Programas ERJ145 e Embraer 170/190 de Furtado e Costa (2006), o desafio que este projeto representou para a empresa foi o mais considerável de sua história, não apenas em termos financeiros, mas, sobretudo, em termos tecnologia de projeto e de produção. Mantendo-se na linha de dominar a tecnologia de projeto da fuselagem, como referenciado por Cassiolato, Bernardes e Latres (2002), a Embraer redistribuiu entre seus parceiros de risco as responsabilidades pelo projeto e a fabricação dos demais elementos da aeronave. A Embraer permaneceria como integradora ${ }^{2}$ da aeronave e coordenadora do projeto. O Programa Embraer $170 / 190$ resultou na aumento de $800 \%$ dos gastos com P\&D (passando de $1 \%$ da receita líquida para $8.1 \%)$, no aumento do número de pessoas nas equipes de engenharia (de 500 para 2.700), tendo mobilizado a empresa e seus parceiros a partir de 1999 e terminando com a certificação da aeronave Embraer 195, em Junho de 2006. Para ultimar as inovações observadas na organização da produção a Embraer adotou um modelo de Gestão do Conhecimento específico para o Programa 170/190, o qual é ilustrado na Figura 2.

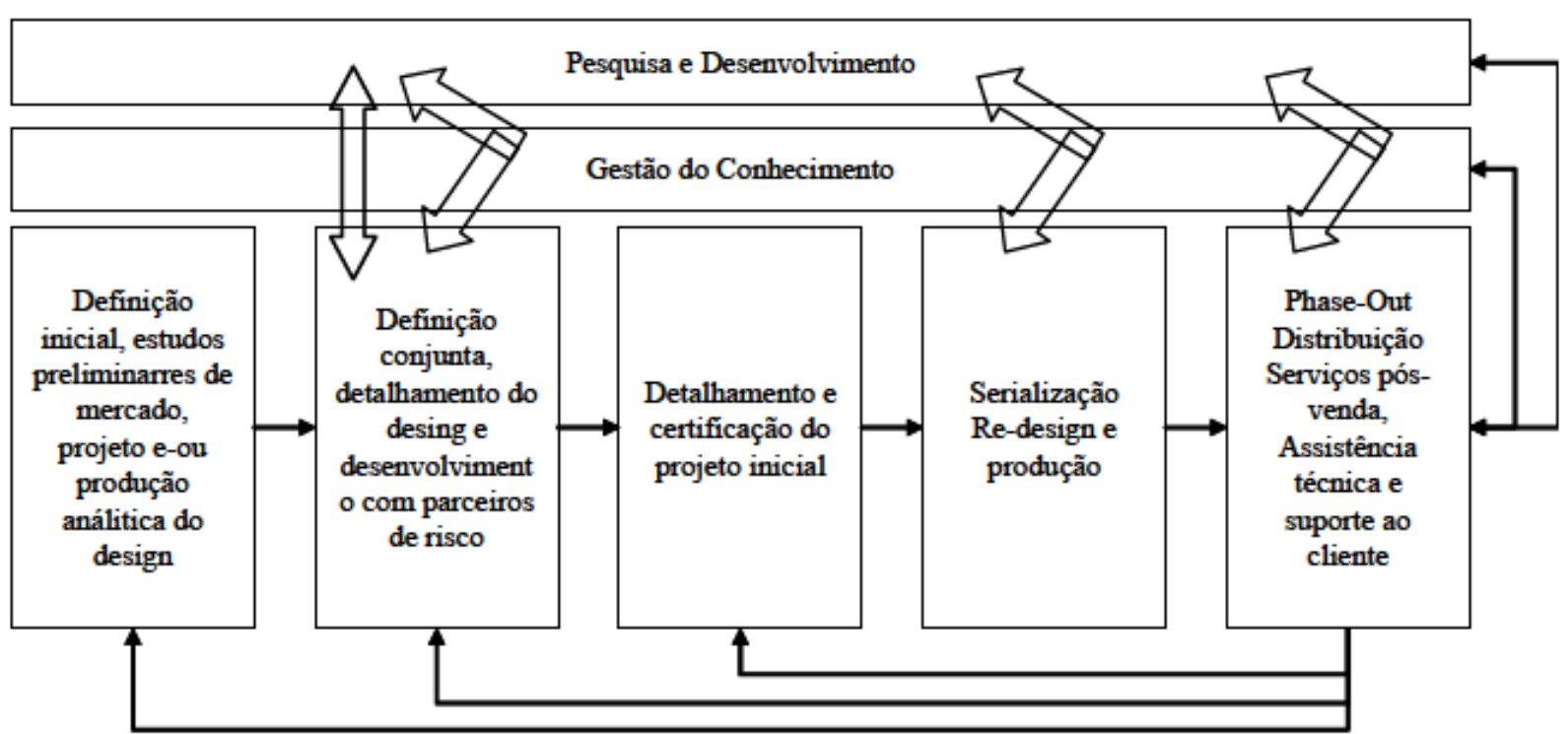

Figura 3 - Modelo de inovação do Programa Embraer 170/190

e) Aprendizado na Embraer - Estratégia de aprendizado: o Learning by hiring na empresa

Segundo Cassiolato, Bernardes e Latres (2002), a Embraer adotou uma estratégia de não apenas dominar o know-how, mas também o know-why da fabricação de aeronaves, tendo seguido um modelo de aprendizado baseado em cinco etapas, correspondendo a períodos históricos de desenvolvimento da empresa, desde o Bandeirante até os programas 145 e 170/190, com alguma sobreposição entre as etapas :

- Aprendizado ao Fazer (Learning by doing) no qual que a aprendizagem ocorre através de feedback a partir da própria atividades de produção.

- Aprendizado pela Adaptação (Learning by Adapting/Changing) - onde o aprendizado ocorre através da adaptação de produtos e processos estrangeiros para o mercado brasileiro. Dagnino (1987) cita especialmente que o contato entre técnicos brasileiros e estrangeiros nos programas Xavante e Piper permitiu uma troca de conhecimento tácito.

- Aprendizado pelo Treinamento (Learning by Training) - Pela formação de profissionais, em vários níveis, desde técnicos até mestres e doutores, atividade fomentada pela CTA e pela própria Embraer, como citado em

- Aprendizado pela Contratação (Learning by Hiring) - Identificado também já a partir dos programas Xavante e Piper, o aprendizado pela contratação iria intensificar-se a partir do programa 145 e 170, sobretudo pela a necessidade de se dominar novas técnicas 
de projeto (Como o CATIA e a Engenharia Simultânea) e produção.

- Aprendizado pela Busca (Learning by Searching) - que corresponde ao aprendizado mediante a pesquisa e ao desenvolvimento a partir de estudos já existentes, num processo de expansão do conhecimento.

No contexto da estratégia para dominar o Know-Why da fabricação de aeronaves, Bernardes (2000, p. 43) destaca a importância que teve o Learning by Hiring para o aprendizado da empresa:

\begin{abstract}
Devemos acrescentar também que no caso da Embraer verificou-se a importância das formas de aprendizado por contratação (Learning by Hiring), que possibilitaram a apropriação de conhecimentos e habilidades através da contratação de empresas ou pessoas". E complementa prevendo que "o desdobramento natural fruto da articulação da estratégia tecnológica com as demais dinâmicas de aprendizagem e a formação de uma cultura técnica e humana transnacional na Embraer será formalização e gestão de um novo modelo de aquisição e renovação permanente do conhecimento corporativo.
\end{abstract}

De Junho a Outubro de 1999, 700 novos engenheiros foram contratados, além de especialistas estrangeiros. Enquanto os primeiros eram normalmente alocados para atividades básicas de engenharia, os últimos, normalmente engenheiros experientes, vinham de diversas partes do mundo para trabalhar como consultores, seja como profissionais autônomos, seja como funcionários de empresa terceirizada.

Particularmente, a contratação de mão-de-obra estrangeira trazia dois obstáculos: o custo muito alto, se comparados à contratação de profissionais locais, e os problemas potenciais de sigilo industrial. No entanto, estes parecem ter sido obstáculos menores face aos resultados obtidos pela empresa com a contratação e a migração de profissionais detentores de conhecimentos que eram necessários ao desenvolvimento dos novos programas de aeronaves. Por meio do Learning By Hiring a Embraer pôde contar, em um curto espaço de tempo, com conhecimentos e tecnologias que somente em longo prazo ela poderia desenvolver por si só, confirmando-se os principais benefícios da busca de conhecimentos externamente à empresa para a aceleração do desenvolvimento interno, apresentados no referencial teórico deste artigo. $\mathrm{O}$ fato de ter a Embraer seguido um modelo sólido de Gestão do Conhecimento foi um fator contribuinte para a conversão e a retenção do conhecimento trazido por estes profissionais. Sem a Gestão adequada deste importante ativo, a ameaça de perda dos conhecimentos adquiridos poderia se transformar em perda real para a empresa. Também é um fator contribuinte para o sucesso da conversão de conhecimentos trazidos pelo Learning by Hiring, a experiência das equipes da Embraer no convívio com estrangeiros que lhe aportaram conhecimentos, o que demonstra que um ambiente propício à conversão do conhecimento torna-a mais eficiente.

\section{Conclusão}

O presente artigo buscou identificar e caracterizar o fluxo de conhecimento criado pela Embraer para o desenvolvimento de suas linhas de aeronaves Embraer 170/190, por meio da contratação de técnicos e especialistas estrangeiros para o projeto. Deste modo, mostrouse que a migração de profissionais estrangeiros foi uma solução adotada pela empresa para o aporte rápido de conhecimentos que, de outra maneira, levar-se-ia muito tempo a desenvolver, tendo a Embraer, como exposto anteriormente, gerenciado de maneira hábil e organizada todo o processo de conversão deste conhecimento, adotando procedimentos e métodos consagrados para atingir os objetivos de transferência e retenção do conhecimento. No entanto, por tratar-se de um assunto ainda pouco explorado no meio acadêmico, e mesmo, no internacional, recomendase o aprofundamento dos estudos sobre o Learning by Hiring e a Migração de profissionais como fatores decisivos para o a conversão de conhecimentos.

Além disto, outras questões para futuras pesquisas se revela, neste momento em que uma crise econômica mundial provoca a eliminação de postos de trabalho técnico e qualificado na própria Embraer: Outras empresas se aproveitarão desta evasão de profissionais em ambiente de crise para praticar o Learning by Hiring a partir do conhecimento criado pela Embraer? Como fará a Embraer para proteger seu Conhecimento da evasão através de um contra-fluxo migratório de profissionais? Tem-se aqui um amplo horizonte de pesquisas.

\section{Notas}

1. Segundo Nonaka (1996), Epistemologia Organizacional é o estudo das formas de conhecimento no âmbito das empresas, e está baseada numa variedade sem precedentes de teorias, proposições e métodos. 
2. Segundo Bernardes (2000), denomina-se Integradora uma empresa que focaliza suas atividades nos elementos-chaves da cadeia de valor de um produto, detendo conhecimento sobre seus sub-sistemas sem, no entanto fabricá-los. A Integradora dedicase a gerenciar uma cadeia de fornecedores de subsistemas para compor um produto final, de seu projeto.

\section{Referências}

AMATO NETO, J.; LUZ, M. C. da; GATTAZ, C. C. The dynamic cooperation network as an instrument for the technological management and innovations process: The case of the Brazilian Aeronautic Sector. Journal of Technological Management Innovation, v 1, n. 3, p. 140-14, 2006.

ARGOTE, L.; BECKMAN, S. L.; EPPLE, D. The persistence and transfer of learning in industrial settings. Management Science, v. 36, n. 2, p. 140154, 1990.

ARGOTE, L.; INGRAM, P. Knowledge transfer: A basis for competitive advantage in firms.

Organizational Behavior \& Human Decision Processes, v. 82, n. 1, p. 150-169, 2000.

ARGOTE, L.; McEVILY, B.; REAGANS, R.. Managing knowledge in organizations: an integrative framework and review of emerging themes. Management Science, v. 49, n. 4, p. 571582, 2003.

BARTLETT, C.A.; GHOSHAL, S.; BIRKINSHAW, J. Transnational management: texts, cases and readings in cross-border management. 4. ed. Boston: Irwin-McGraw-Hill, 2004.

BERNARDES, R. O caso Embraer: privatização e transformação da gestão empresarial: dos imperativos tecnológicos à focalização no mercado. Cadernos de Gestão Tecnológica, n. 46, CYTED/PGT/USP. São Paulo, 2000.

CASSIOLATO, J. E.; BERNARDES, R.; LATRES, $\mathrm{H}$. Transfer of technology for successful integration into global economy: A case study of Embraer. UNCTAD/ITE/IPC Misc, New York, n. 20, 2002.

DAFT, R.L. Organizações: teorias e projetos. São Paulo. Thomson-Pioneira. 2002.

DAGNINO, R.. A indústria de armamentos brasileira: uma tentativa de avaliação. Tese de Doutoramento apresentada ao Instituto de Geociências - UNICAMP, Campinas. 1987.

DAGNINO, R. A Indústria Aeronáutica - estudo da competitividade da indústria brasileira. Nota Técnica Setorial. Campinas IE/UNICAMP/MCT/FINEP/PACDT. 1993.
DAVENPORT, T; PRUSACK, L. Conhecimento empresarial: como as organizações gerenciam seu capital intelectual. 2. ed. Rio de Janeiro. Campus. 1998.

DOSI, G.. Technological paradigms and technological trajectories: a suggested interpretation of the determinants and directions of technical change. Research Policy, n. 11, p. 147162, 1984

DRUMOND, C. D. Asas do Brasil: uma história que voa pelo mundo. São Paulo: Cultura, 2004.

EMBRAER. Site Internet www.embraer.com.br. Consultado em 2009.

ETTLIE, J. E. The impact of interorganizational manpower flows on the innovation process. Management Science, v. 31, n. 9, p. 1055-1071, 1985.

FURTADO, A. T.; COSTA FILHO, E. J. Relatório final - atividade 4: avaliação dos impactos sócioeconômicos dos programas ERJ145 e 170/190 da EMBRAER. Campinas: Estudo da Cadeia Produtiva Aeronáutica Brasileira, 2006.

GÓES, R.; LACOMBE, M.I. Embraer: Delivery disappointment, robust backlog. UBS Investment Research, Banco UBS Pactual, 2007. 5 p.

GRANT, R. Towards a knowledge-based theory of the firm. Strategic Management Journal $N^{0} 17$, págs 109-122. 1996.

GRANT, R.. "Knowlegde and Organization" em Managing industrial knowledge: Creation, transfer and utilization. Sage: London, 2001.

GRANT, R. Contemporary strategy analysis. 10. ed. Boston: Marden, 2005.

HOWELLS, J.; JAMES, A.; MALIK, K. The sourcing of technological knowledge: distributed innovation processes and dynamic change. R \& D

Management, v. 33, n. 4, p. 395-409, 2003.

JAFFE, A. Technological opportunity and spillovers of R\&D: evidence from firms' patents, profits, and market values. American Economic Review, v. 76, n. 5, p. 984, 1986.

JOÃO, B. N.; FISCHMAN, A. Estratégias baseadas no conhecimento na Embraer: um estudo de caso. São Paulo: Série de Working Papers, 04/011. USP, 2000.

KIM, L. The dynamics of Samsung's technological learning in semiconductors. California Management Review n. 39 p. 86-100. 1997.

KOGUT, B.; ZANDER, U. Knowledge of the firm: combination capabilities and the replication of technology. Organizational Science. N³ p. 383397. 1992. 
MAHROUM, S. Highly skilled globetrotters: mapping the international migration of human capital. R \& D Management, v. 30, n. 1, p. 23-32, 2000.

MANSFIELD, E.. Industrial research and technological innovation: An econometric analysis. Norton: New York. 1968.

MENON, T.; PFEFFER, J.. Valuing internal versus external knowledge. Management Science, n. 49 p. 497-513. 2003

NADLER, J.; THOMPSON, L.; VAN BOVEN, L. Learning negotiation skills: four models of knowledge creation and transfer. Management Science, v. 49, n. 4, p. 529-540, 2003.

NELSON, R.; WINTER, S. G. An evolutionary theory of economic change. Cambridge: Harvard University Press, 1982.

NONAKA, I. The knowledge-creating company. Harvard Business Review, v. 69, n. 6, p. 96-105, 1991.

NONAKA, I.; TAKEUCHI, H. Criação de conhecimento na empresa: como as empresas japonesas geram a dinâmica da inovação. Rio de Janeiro: Campus, 1997.

NONAKA, I.; VON KROGH, G.; VOELPEL, S. Organizational knowledge creation theory: evolutionary paths and future advances.

Organizational Studies, v. 27, n. 8, p. 1179-1208, 2006.

SANTOS, J.; DOZ, Y.; WILLIAMSON, P. Is your innovation process global? Sloan Management Review, v. 45, n. 4, p. 31-37, 2004.

SBRAGIA, R. E.; TERRA, J. C. C. EMMBRAER: Trajetória de uma empresa de alta tecnologia brasileira. Cadernos de Gestão Tecnológica. NPGCT/USP, n. 8, São Paulo, Dezembro/1993.

SONG, J.; ALMEIDA, P.; WU, G. Learning-byHiring: When is mobility more likely to facilitate inter-firm knowledge transfer? Management Science. v. 49, n. 4, p. 351-365. 2003.

STARBUCK, W. H. (1992). Learning from knowledge intensive firms. Journal of Management Studies, v. 29, 1992.

STEHR, N.. Practical knowledge: Applying the social sciences. Sage: London, 1992.

SZULANSKI, G. Exploring internal stickness: impediments to the transfer of best practice within the firm. Strategic Management Journal, v. 17, p. 27-43, 1996.

WONG, V.; SHAW, V.; SHER, P. J. Intra-firm learning technology transfer: a study of Taiwanese
Information Technology Firms. International Journal of Innovation Management, v. 3, n. 4, p. 427-458, 1999.

YIN, R.K. Estudo de caso: planejamento e métodos. 2. ed. Porto Alegre: Bookman, 2004.

ZANDER, U.; KOGUT,B.. Knowledge and the speed of transfer and imitation of organizational capabilities: An empirical test. Organizational Science, n. 6, p. 76-92. 1995.

ZALENICK, A. Organizational reality and psychological necessity in creativity and innovation. In: Frontiers in creative and innovative management. Ballinger: Cambridge, 1985. 